\title{
Lifelong Education: Global Approach
}

\author{
Ana Stavljenic-Rukavina, Elizabeta Topic
}

\begin{abstract}
Lifelong learning became the most important issue in new strategies of education in global world. In health services education is focused on bringing fast new technological development into clinical practice assuring patient's safety. To make lifelong learning in health care professions a reality, education and training systems should make a stronger effort toward really open, flexible and transparent education. This requires co-operation between E uropean, national and regional/ local levels, but it also calls for quality assurance systems to strengthen their co-operation on these objectives. The multidisciplinary approach in lifelong learning is particularly important in health system where patient's problems are in the center of their activities. Interdisciplinarity in practice, collaboration, co-ordination of continuity of care are as important for health system as for individual patient. Therefore, lifelong learning is ultimate goal for everyone working in health sector. Higher education quality assurance mechanisms should support lifelong learning by a broader international dimension, providing transparency and recognition, better adapting to nontraditional education and learners, and encouraging bridges with other education levels and sectors (in particular with vocational education and training). This should be complemented with incentives for higher education institutions to become more active in lifelong learning, and to a broad range of stakeholders in that process.
\end{abstract}

Keywords: Lifelong learning, Continuous education, Interprofessional education, P oint of care, Lifelong learning program development, Quality assurance, Continuous professional development.

How to cite this article: Stavljenic-Rukavina A, Topic E. Lifelong Education: Global Approach. Donald School J Ultrasound O bstet Gynecol 2013;7(3):296-300.

\section{Source of support $\mathrm{Nil}$}

Conflict of interest: None declared

\section{INTRODUCTION}

The strategic framew ork for co-operation in education and training for 2020 focuses on four key areas:

- Making lifelong learning ( $L L L)$ and mobility a reality [including a European benchmark that by 2020 at least $15 \%$ of adults (age group 25-64) should participate in LLL]

- Improving the quality and efficiency of education and training

- Promoting equity, social cohesion and active citizenship, and

- Enhancing creativity and innovation, including entrepreneurship. ${ }^{1}$

Given the need for Europe to raise skill levels and provide high quality education and training, it is no coincidence that $L L L$ and quality assurance figure as two of these priorities.

LLL approaches refers to an individual's opportunity to acquire knowledge, qualifications and skills throughout his or her life, as well as the capacity to have his/her prior learning recognized (whether personal, civic, social, professional or employment-based learning). ${ }^{2} \mathrm{~L} L \mathrm{~L}$ must be exemplified by a universal right to $L L L$ based on a set of training schemes open to a wide range of learners. This broad definition means a shift in perspective for all education system players. Indeed, LLL training needs are heterogeneous, persistent, targeted and individualized and involve the whole population. In that context and in order to address the challenge that represents these diverse and specific needs, it is essential to develop a set of integrated and flexible programs that can cope with individual and collective needs. ${ }^{3}$

However, in health care professions $L L L$ has been recognized as ultimate need long time ago and since many years has been provided through professional associations or universities. ${ }^{4}$ This includes the continuum of health professional education from admission into a health professional program to retirement that values, exemplifies, and assesses LLL skills; emphasizes interprofessional and team-based education and practice; employs tested, outcomes-based continuing education methods; and links health professional education and delivery of care within the workplace. The $L L L$ process in health professions is accelerated in last decade due to impressive advancement in new technologies and medical products development. In order to reach the successful and adequate knowledge in real time with all new discoveries in diagnosis and treatment, it is necessary to encourage an understanding of and support for the need for change, and collaboration among stakeholders responsible for the interdependent LLLacademic institutions, health care systems, continuing education providers, accrediting bodies, licensing and credentialing boards, funders and others. ${ }^{5}$

\section{Lifelong Learning in Health Care System}

Heal th care systems, capacities and financing differs among countries/continents and for that reason LLL cannot be uniform for all countries in spite of the fact that new technologies are available overall the world. M eaningful health care reform is undertaken in many countries today and its implications pose many challenges for health 
professionals and the health care system. These include, among other issues, advancing health care quality, delivering safe and cost-effective patient-centered care, increasing access to care through the use of information/ communication technology, changes in insurance coverage and effective use of the health professional workforce. Geographic variations and workforce shortages pose additional challenges to achieving health care reform. Realizing these expectations cannot occur absent commitment to and reinvestment in individually focused and teamand organizationally based $L L L$ and continuing education. Where learning organizations exist, teams and individuals practicing in those settings are exposed to feedback and improvement practices, which enrich individual knowledge. ${ }^{4-6}$

In the process of examining the roles of and potential impact on key stakeholders in the process of producing, accrediting, and supporting continuing education and $L L L$, several important questions were raised and processed. ${ }^{2}$

- A re health care professions on country level regulated by law (including licensing, accreditation, credit system)?

- If there were no accreditation or credit systems, how would the professions monitor quality/accountability for individuals, teams and the system? One approach might be to document and monitor the health professional's progress in achieving learning goals: e.g. by portfoliobased activities, a process that could be consistent across professions.

- What is the proper balance between current practices in LLL, captured by the term evidence-based vsinnovation?

- What funding would be needed to implement the changes recommended?

- To support changes in continuing education practices, how can creative, innovative and personalized faculty development best be implemented and supported?

- To what extent international co-operation might improve or harmonize $L L L$ process for health care workers on regional or country level?

$L L L$ process outcomes depend to a great extent on support of stakeholders as governmental bodies responsible for education and law regulation and licensing bodies responsible for altering requirements for the competency of academic programs and continuous education (CE) in the first line. Health care accreditation systems and other stakeholders in health care system are aimed to support the implementing these recommendations into continuous practice. $^{2}$

The success of $L L L$ programs depends further on educational accreditation bodies examining and supporting the creation of effective and critically thinking of lifelong learners. The role of faculties and other academic institutions as leaders is to support and foster all activities leading to the development of more effective, innovative and accountable LLL learners.

Professional organizations as $L L L$ providers have very important role in changing their priorities to advancing the variety of $L L L$ programs.

$L L L$ to some extent overlaps with CE in health profession held by professional organizations in form of conferences, rounds, courses and in-service trainings. CE is a formal transmission of predetermined body of knowledge frequently provided with designated accreditation and generate 'credits' to practitioners necessary for their obligate licensing or credentialing processes (Fig. 1). ${ }^{7}$

A nother method for achievements of new skills is workplace learning which might be defined as the way in which individuals or groups acquire, interpret, reorganize, change or assimilate a related cluster of information, skills and feelings, and a means by which individuals construct meaning in their personal and shared organizational lives. ${ }^{8}$

Point-of-care learning as a part of workplace learning comprises activities occurring at the time and place of a clinician-patient visit, and therefore is most often distinguished by its context; the active encounter between the clinician and the patient in the health care site, home, or elsewhere. It is during this process that information needs are identified and the opportunity for clinician and patient education, clinical decisions, and patient management intersect. It is important for patient centered care approach today.

On the contrary, LLL process for health professionals has a broader mission and multidimensional methodology. $L L L$ for health professionals includes interprofessional learning experience in both didactic and clinical components of the curriculum designed and performed collaboratively,

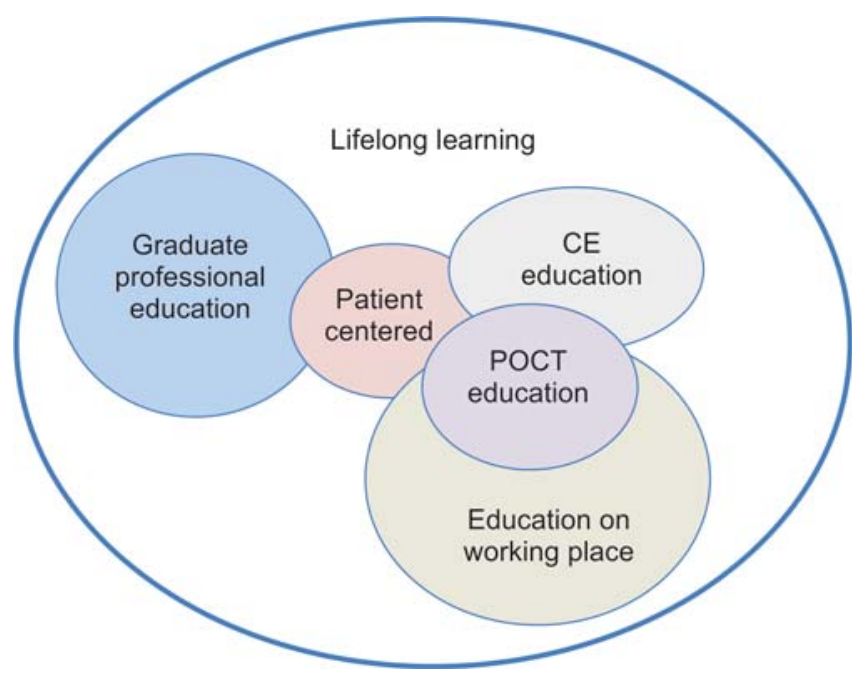

Fig. 1: Lifelong learning 
role-modeling interprofessional practice ${ }^{9,10}$ Interprofessional learning and practice experiences continue throughout advanced education training and clinical components programs who have documented knowledge and skills that prepare them to engage in meaningful LLL experiences throughout their careers.

The vision for a preferred $L L L$ puts on health professions organizations, academic institutions, policy makers, insurers, CE providers and regulatory bodies the need to embrace an interprofessional education (IPE) model. ${ }^{11} \mathrm{This}$ model should be patient-centered, flexible and encompassing a significant and measurable component across the educational continuum from entry into health professional education throughout one's career.

\section{The Value of Lifelong Learning in Health Care}

Since, health care system is one of the most complex one in almost every country and today oriented to patient-centered care of the highest and measurable quality where patients are partners and at the same time important stakeholders in $L L L$ programs development. For health professions $L L L$ is viewed 'lifelong, life wide, voluntary and self-motivated' pursuit of knowledge for either personal or professional reasons. As such, $L L L$ enhances social inclusion, active citizenship and personal development.
LLL can be viewed in two ways: first, as a value embraced by the broad community of health professionals and, second, as behavior advocated by health professional organizations and adopted by many individual health professionals. Its value and acceptance is modified by preprofessional experiences, which may lead to an individual's adoption of knowledge management, information retrieval and related skills. V aluing these skills is a necessary precursor to the translation of evidence into practice. The construct has gained increased attention in the health professions, a product of the accelerated pace of developments in the science and technology of health care and growing concerns about maintaining and enhancing quality of care in an increasingly complex practice environment. The process of $L L L$ can bring personal satisfaction and even joy to learning and practice, can enhance professional identity and value, and may prevent burnout. $^{12}$

\section{Case Study in LLL for Laboratory Medicine Profession using the Model of Interprofessional Education}

The organizers of $L L L$ are academic institutions, professional associations and other stakeholders. L aboratory medicine is a good example of profession where their service

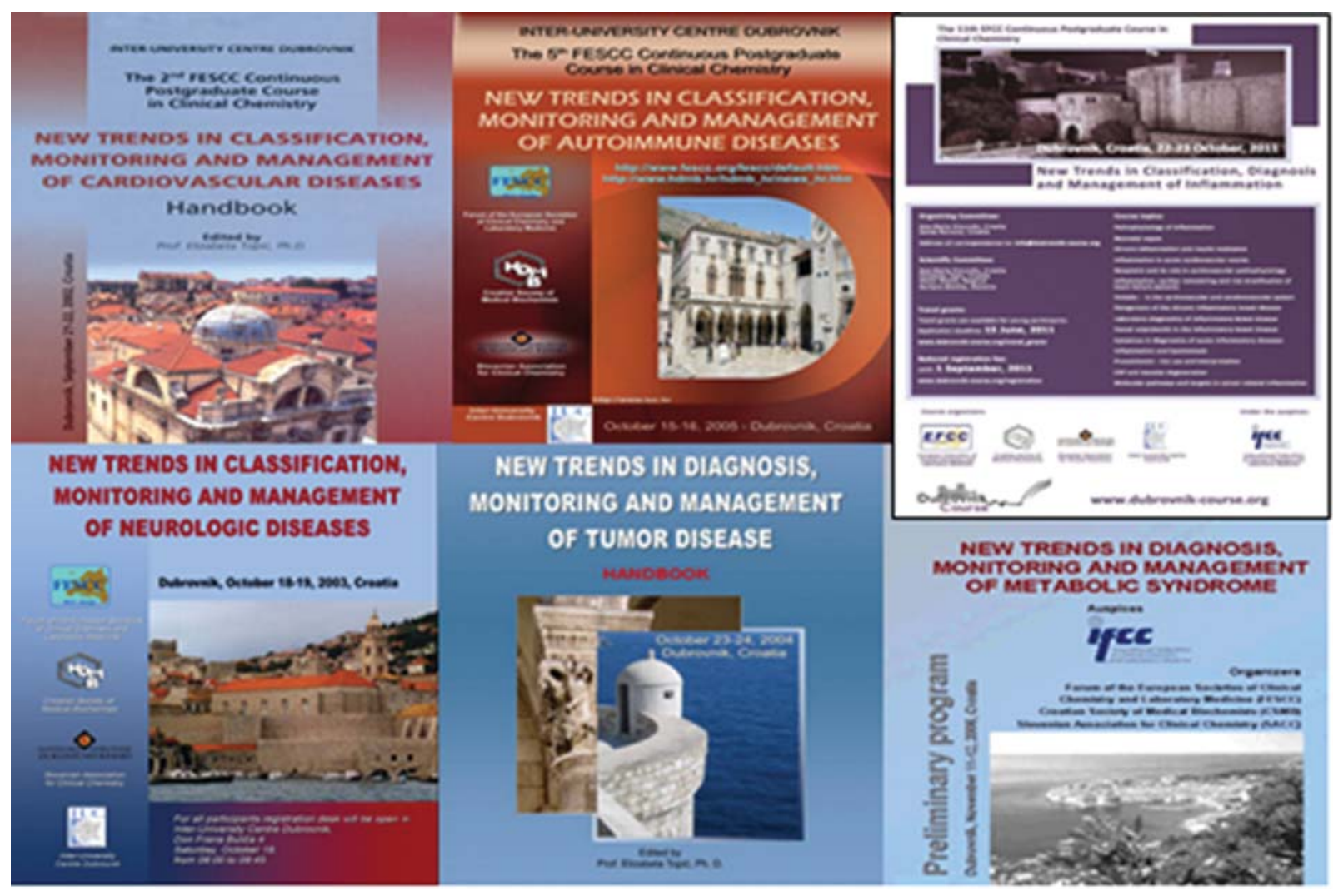

Fig. 2: International education in laboratory medicine 
is used by all health professions in diagnosis and treatment of almost all health problems of their patients. Laboratory medicine is constantly undergoing significant changes, due to new medical information, scientific results and development of novel technologies. In order to ensure the best possible laboratory service to the patient, it is mandatory for laboratory professionals to keep abreast with all these changes. The most appropriate way to achieve this goal is integration of continuous professional development (CPD) in the clinical laboratory education continuum. But at the same time all research developments in this profession belong to or better to express, it cannot be implemented for patient care without very broad exchange of knowledge with all other medical professions. In addition laboratory medicine is present in POCT and used by patient themselves. In last decades number of new technologies has changed the volume and range of laboratory tests including molecular diagnostics. Fast growing new knowledge on potential benefits and risks in using molecular and genetic testing is the reason why IPE of all-medical doctors of different specialties, nurses, patients and their families- becomes more important. Here is one case study representing the European approach to $L L L$ in laboratory medicine (Fig. 2).

Since, 10 years European federation for clinical chemistry and laboratory medicine, together with Croatian association for medical biochemistry and laboratory medicine, and under the auspices of International federation of clinical chemistry, is organizing $L L L$ program using model of IPE and systematically oriented to multidisciplinary discussion on new technological developments for diagnosis and follow-up treatment of different health problems. ${ }^{13}$ The hosting institution International U niversity Center (IUC) Dubrovnik is an independent international institution for advanced studies structured as a consortium of universities with a mission to organize and promote contacts and exchange through projects study programs, courses and conferences across a wide range of scientific concerns. The network and resource persons coming from about 170 member universities worldwide co-operate in organizing the activities. In 10 years LLL program for laboratory medicine has become, because of quality of program and teachers, recognized in the region and Europe through its approach to interprofessional model of education. A number of participants from the region and other European countries are coming year by year to IUC to be active learners in particular field of new and advanced diagnostic and therapeutic procedures. The creative environment, multidisciplinary world recognized lecturers and the quality of teaching methodol ogies are main reasons for participants to be present again every year. L ooking at programs along these 10 years and topics covered by interdisciplinary lecturers it is undoubtedly an UE and global example of LLL program.

\section{Quality Evaluation of LLL Programs}

IPE methodology is not only useful for $L L L$. Today's reforms of health systems are focused on new approach in medical practice as well. There is evidence which supports the notion that IPE is to be integrated into the culture of health professional academic programs to foster health professional collaboration in care delivery. ${ }^{2,7}$ This culture shift would create a framework for health professions' education that incorporates and builds upon common values and goals related to patient-centered care, mutual respect, effective communication and knowledge regarding health professional roles and responsibilities. Co-operation, collaboration and co-ordination become ultimate goals for quality of care. M ore and more is IPE education incorporated into health profession's curricula. LLL methods and achievements become important issue on international level conferences, only this year (2013) more than 60 conferences and congresses are foreseen focused on that topic.

Quality assurance mechanisms need to be established to ensure that the existing provision for $L L L$ fulfills its aims. ${ }^{14} \mathrm{~A}$ number of tools have proved to be useful for this task, such as the European key competences framew ork for $L L L$; the European qualifications framework, complemented by national qualifications frameworks based on learning outcomes being developed by member states and the European guidelines for validating informal and nonformal learning, the European inventory on validation of informal and nonformal learning, and the open method of co-ordination. The key to success and to ensuring optimum impact of these tools is co-operation between stakeholders from all levels and sectors relevant for $L L L$, in particular between education and training, employment and social affairs, and across national, regional and local levels.

A particular and strategic objective of the European Union's Program for $L L L$ includes improving the quality, appeal and accessibility of the $L L L$ programs. This provides a direct link to quality assurance in $L L L$. The accreditation system plays an important role in terms of quality assurance. The accreditation of degree programs is an internationally established quality assurance process in the higher education sector. It serves to maintain fundamental standards in terms of the contextual and structural design of educational offerings, to secure the comparability of various study programs at national and international level, and to facilitate the international recognition of academic achievements and degrees. 


\section{REFERENCES}

1. Fletcher SW . Chairman's summary of the conference. In: Hager $M$, editor. Continuing education in the health professions: improving healthcare through lifelong learning. Nov 28 - Dec 1 2007; B ermuda. N ew Y ork: J osiah M acy, J r F oundation; 2008.

2. Greiner $A C, K$ nebel $E$. Health professions education: a bridge to quality. Washington, DC: National A cademies Press; 2003. p. 76-96.

3. Institute of M edicine. L earning healthcare system concepts $v$. 2008. A nnual Report. Washington, DC: Institute of M edicine of the N ational A cademies. A vailable from: http://www.iom.edu/ /media/Files/A ctivity\%20Files/Q uality/V SRT/L earning\%20 Heal thcare \%20System\%20Concepts\%20v2008. pdf. A ccessed: July 30, 2009.

4. Forsetlund L, B jørndal A, Rashidian A, Jamtvedt G, O'Brien $M A$, W olf F, Davis D, Odgaard-Jensen J, Oxman AD. Continuing education meetings and workshops: effects on professional practice and health care outcomes. Cochrane Database Syst Rev 2009; A pr;(2):CD 003030.

5. Association of A merican M edical Colleges. Educating doctors to provide high quality medical care: a vision for medical education in the U nited States. W ashington, DC: A ssociation of A merican M edical Colleges; 2004. 1-12 p.

6. Accreditation Council for Continuing Medical Education. Continuing education as a bridge to quality: leadership, learning, and change within the $A C C M{ }^{\circledR}$ system. Chicago, IL: A CCM E; 2008. p. 5-16.

7. M arinopoulous $S S$, Dorman $T$, R atanaw ongsa $N$, W ilson $L M$, A shar B H, M agaziner J L, M iller RG, Thomas PA, Prokopowicz GP, Q ayyum R, Bass EB. Effectiveness of continuing medical education. Evid Rep Technol Assess (Full Rep) 2007 Jan;(149):1-69.

8. Zwarenstein M, Reeves S, Barr H, Hammick M, K oppel I, A tkins J. Interprofessional education: effects on professional practice and health care outcomes. Cochrane Database Sys Rev 2008;(1):CD 002213.
9. Headrick LA. Learning to improve complex systems of care. In: Collaborative education to ensure patient safety. W ashington, DC: HRSA/B ureau of Health Professions; 2000. 75-88 p.

10. HoK, J arvis-Selinger S, Borduas F, Frank B, Hall P, H andfieldJ ones R, Hardwick DF, L ockyer J, Sinclair D, Lauscher HN, et al. $M$ aking interprofessional education w ork: the strategic roles of the academy. A cad M ed 2008 Oct; 83(10):934-940.

11. Retchin SA. Conceptual framework for interprofessional and co-managed care. A cad M ed 2008 Oct;83(10):929-940.

12. Plesk P. Complexity and the adoption of innovation in health care. Washington, DC: National Committee for Quality Health Care; J anuary 27-28, 2003. A vailable from: http://www. nihcm. org/pdf/PIsek.pdf. A ccessed: J uly 30, 2009.

13. Topic E, Beletic A, Zima T. The continuous professional development crediting system in the profession specialist in laboratory medicine among EFL M societies. B iochemia M edica 2013;23(3):In print.

14. Bengoetxea E, K allioinen O, Schmidt-J ortzig I, Thorn R. Q uality assurance in lifelong learning. ENQA W orkshop Report 18. Belgium, B russels: European A ssociation for Q uality A ssurance in Higher Education; 2011.

\section{ABOUT THE AUTHORS}

\section{Ana Stavljenic-Rukavina}

Professor, Dubrovnik International University, School of Health Sciences, Croatia

CorrespondenceAddress A na Stavljenic-R ukavina, A ugusta Senoe 27, Zagreb, Croatia, Phone: +385 1 4923037, e-mail: ana.stavljenicrukavina@zg.t-com.hr

\section{Elizabeta Topic}

School of Pharmacy and M edical Biochemistry, EFLM Committee of Education and Training, U niversity of Zagreb, Croatia 